\title{
UM LUGAR CHAMADO MACONDO
}

\author{
Ghiovana da Rosa Machado Cruz \\ Mestra pelo Programa de Pós-Graduação em Estudo de Cultura e Território (PPGCULT) da \\ Universidade Federal do Tocantins - UFT \\ ghiovanacruz@gmail.com
}

\section{RESUMO}

O texto deste artigo compõe dissertação de mestrado do programa de pósgraduação em estudo de cultura e território pela Universidade Federal do Tocantins (PPGCULT- UFT). Buscamos fazer uma análise na perspectiva fenomenológica da obra Cem anos de solidão do escritor colombiano Gabriel García Márquez. No artigo aqui apresentado a nossa intenção será analisar Macondo (que é a aldeia, posteriormente cidade, criada pelo escritor colombiano) como lugar-literáriosimbólico. Daremos destaque para a casa dos Buendía e a sua importância no romance, como a mesma, também, se constitui lugar. Nos apoiando em Dardel (2011), Eliade (1992), Tuan (2012), Bachelard (2008), Marandola Jr (2010), teceremos nossa interpretação de alguns aspectos ligados à constituição do lugar, presentes no romance em estudo.

Palavras-chave: Cem anos de solidão;

Macondo; Casa dos Buendía;

Fenomenologia.

\section{RESUMEN}

El texto de este artículo compone disertación de maestría del programa de posgrado en estudio de cultura y territorio por la Universidad Federal de Tocantins (PPGCULT- UFT) en producción. Buscamos hacer un análisis en la perspectiva fenomenológica de algunos elementos presentes en la obra Cien años de soledad del escritor colombiano Gabriel García Márquez. En el artículo aquí presentado nuestra intención será analizar Macondo (que es la aldea, posteriormente ciudad, creada por el escritor colombiano) como lugar-literario-simbólico. Daremos destaque a la casa de los Buendía y su importancia en la novela, como la misma, también, se constituye lugar. Nos apoyamos en Dardel (2011), Eliade (1992), Tuan (2012), Bachelard (2008), Marandola Jr (2010) tejeremos nuestra interpretación de algunos aspectos ligados a la constitución del lugar presentes en la novela en estudio.

Palabras clave: Cien años de soledad; Macondo; Casa de los Buendia; Fenomenología. 


\section{INTRODUÇÃO}

(...) rumo à terra que ninguém havia prometido. (GARCÍA MÁRQUEZ, 2016, p. 65)

O que é Macondo para estrutura narrativa do romance do colombiano Gabriel García Márquez? Seria muito vão considerá-la apenas como cenário fictício para o desenvolvimento do enredo da família Buendía.

Todas as cidades da ficção normalmente são essenciais para o mundo onde um livro/ história se passa, complementando ou reforçando as características dos personagens e dos eventos ocorridos. A geografia física e humana constituem a sobreposição histórica do homem com o espaço, tornando-os um. Macondo não é apenas um chão, um lugar de passagem ou moradia. Com suas amendoeiras eternas, chuvas intermináveis e secas desoladoras a cidade é tão presente na narrativa da secular história que se faz como personagem da mesma.

\section{Macondo}

Macondo era então uma aldeia de vinte casas de pau a pique e telhados de sapé construídas na beira de um rio de águas diáfanas que se precipitavam por um leito de pedras polidas, brancas e enormes como ovos pré- históricos. O mundo era tão recente que muitas coisas careciam de nome, e para mencioná-las era preciso apontar com o dedo. (GARCÍA MÁRQUEZ, 2016, p. 43)

O romance é iniciado com essa descrição da aldeia o que passa ao leitor uma ideia de novidade, de nascimento, de novo. Tudo era muito recente, como as personagens que buscavam uma "vida nova" com sua odisseia, assim também era o lugar onde eles se 
encontravam. Renovação, possibilidades, são essas as imagens transmitidas logo no início de Macondo, de uma esperança que, por fim, será frustrada.

A aldeia nasce devido a um episódio criminoso, que resulta em uma perseguição sobrenatural silenciosa e constante do fantasma de Prudêncio, morto por José Arcádio Buendía. “Certa noite em que o encontrou lavando as feridas em seu próprio quarto (...) Está bem, Prudêncio - disse ele. - Vamos embora deste lugar o mais longe que a gente conseguir, e não voltaremos nunca mais. Agora, vá embora tranquilo" (GARCÍA MÁRQUEZ, 2016, p. 65). Prudêncio Aguilar, na perda da briga do galo, gritou a todos que Úrsula permanecia virgem - por medo de parir não humanos devido ao próximo laço sanguíneo com o marido - depois de mais de ano de casamento, o que gerou humilhação e ira no patriarca dos Buendía, resultando na morte de Prudêncio.

José Arcádio Buendía volta então para casa, após matar Prudêncio Aguilar com a lança, transtornado com o desaforo recebido e principalmente com a atitude assassina que foi impelido a tomar.

José Arcádio Buendía entrou no quarto quando sua mulher estava vestindo a calça de castidade. Brandindo a lança na frente dela, ordenou: "Tire isso." Úrsula não pôs em dúvida a decisão do marido. "Haja o que houver, a responsabilidade será sua", murmurou. José Arcádio Buendía cravou a lança no chão de terra. - Pois se você tiver que parir iguanas, criaremos iguanas - disse ele. - Mas nesta aldeia não haverá mais mortos por sua culpa. (GARCÍA MÁRQUEZ, 2016, p. 63)

O casal está ligado muito mais do que por um sentimento de amor, estão condenados pela culpa e assim fundamentaram seu casamento e, consequentemente, sua família. Assistiriam quase imóveis, à passagem de cem anos de uma irreparável solidão. O medo encucado pela mãe de Úrsula na filha sobre ter filhos mutantes não se 
concretiza, mas as características psicológicas, loucura e solidão, se fazem tão fortes em toda prole quanto o rabo de porco ou as temidas iguanas.

Entendemos Macondo como lugar-literário-simbólico. Para isso nos apoiamos numa perspectiva humanista da geografia, a qual afirma que os lugares são centros aos quais atribuímos valor. Não são as proporções físicas que constroem a essência e o valor do lugar, mas a natureza da experiência humana, bem como o grau e qualidade da ligação emocional e a afetividade envolvida nesse processo.

Não são apenas os aspectos materiais que constroem o lugar. O lugar é um modo particular de relacionar as distintas experiências espaciais. É dito particular por ter a capacidade de atrair e concentrar as intenções.

O lugar está intimamente relacionado ao tempo. Seu sentido implica o sentido da vida e, por sua vez, o sentido do tempo. Essa categoria é vital na construção de outros conceitos espaciais. Sua construção de sentido está interligada aos símbolos referenciais com seus significados e permanências. Espaço e lugar expressando, metafórica e respectivamente, as noções de penumbra e claridade, personificados a partir das experiências, ambiguidades e valores humanos, manifestam níveis distintos de especificidade. O espaço estaria mais ligado ao movimento e o lugar a pausa.

No início de seu artigo "Humanismo e arte para uma geografia do conhecimento" (2010), Marandola Jr cita John K. Wright, em seu discurso presidencial da Associação dos Geógrafos Americanos (1946). Neste, o mesmo ressalta a importância da imaginação para o conhecimento dos geógrafos. Wright "aponta seriamente para a importância de olharmos para 'além das fronteiras', onde outros também produzem conhecimento geográfico de relevância." (MARANDOLA JR, 2010, p. 8). Com isso podemos perceber a importância de buscar o conhecimento geográfico para além das fronteiras disciplinares 
do saber acadêmico. Reforça quando afirma que não são apenas os geógrafos que necessitam ampliar suas fronteiras, enumera algumas outras áreas do conhecimento em que a utilização de dados "não científicos" também são bem-vindos, como na história, sociologia, filosofia, psicologia e antropologia.

Para avançar as fronteiras entre o que é definido como científico ou não, nada mais adequado do que o olhar de um artista, pois a arte é sensível ao que lhe cerca. 0 artista consegue produzir importantes leituras e construções da realidade, as quais projeta em sua obra. Devido a sua capacidade perceptiva, suas experiências e vivências inova, cria e recria.

\footnotetext{
Ligação direta do homem com o mundo, a cor ligada ao movimento e à substância nos permite "ver" imediatamente o desabrochar das flores, a maturidade dos frutos, a aridez do deserto, a dureza do granito. O transbordamento das coisas para fora delas mesmas, ao nosso encontro, nos outorgam parte do próprio ritmo do mundo, das forças em luta. (DARDEL, 2011, p. 39)
}

Pode-se perceber uma releitura através de um olhar artístico, cores e poesia na descrição de acontecimentos geográficos sobre a ligação íntima entre homem e natureza. Através do poema nos olhos de quem narra e ritmo nas palavras expostas é possível, através da arte, narrar como se dá a relação homem/ natureza.

“Arte é pensamento, construído e materializado num determinado símbolo imagem. (...) A obra de arte é, portanto, uma realidade dominada, com o uso de técnicas, recursos, convenções, sentidos e emoções." (MARANDOLA JR, 2010, p. 15-16) Sendo assim, a arte não pode ser considerada um simulacro da realidade, não pretende ser mera imitação do que é considerado real. Ela é um processo de criação, de subjetividade aflorada. Mesmo com toda a subjetividade que compõe o processo criativo artístico, a 
mesma ainda tem amarras com o contexto social e a história em que o artista está inserido, no entanto sem se limitar a questões temporais ou até mesmo sociais. A arte diz sobre questões cotidianas, e também diz mais, vai além, transcende.

\begin{abstract}
Nas obras de arte, vemos inscritas as duas dimensões que aparentemente se confrontam: o material e o simbólico, o racional e o intuitivo. Contudo, essa diametria precisa ser melhor refletida, pois o material sem o simbólico inexiste e o simbólico, conforme aponta Mukarôwvský (1993), embora subsista sem o material, não se torna uma manifestação, veículo de cultura e comunicação, sem uma dada materialização. (MARANDOLA JR, 2010, p. 17)
\end{abstract}

Falando sobre arte, podemos nos aportar sobre a discussão feita por Heidegger a respeito da obra de arte. O filósofo considera como lugar privilegiado em que a inauguração do mundo ganha destaque. A obra de arte é palco para a subjetividade do artista, nada é criado do nada. Há uma relação mútua entre imaginário e realidade, criação e imitação. O processo de criação e recriação é cíclico e contínuo, as coisas ganham seus significados e consequentemente sua representação através da teia de sentidos em que o grupo social se encontra.

Ser obra quer dizer: instalar um mundo. Mas o que é isso, um mundo? (...) Mundo não é a simples reunião das coisas existentes, contáveis ou incontáveis, conhecidas ou desconhecidas. Mas mundo também não é uma moldura meramente imaginada, representada em acréscimo à soma das coisas existentes. O mundo mundifica (Welt weltet) e é algo mais do que o palpável e apreensível, em que nos julgamos em casa. Mundo nunca é um objeto, que está ente nós e que pode ser intuído. O mundo é o sempre inobjectal a que estamos submetidos enquanto os caminhos do nascimento e da morte, da bênção e da maldição nos mantiverem lançados no Ser. Onde se jogam as decisões essenciais da nossa história, por nós são tomadas e deixadas, onde não são reconhecidas e onde de novo são interrogadas, aí o mundo mundifica. (HEIDEGGER, 1977, p. 35)

A produção artística faz criar um novo mundo formado a partir de influências recebidas pelo artista e sua subjetividade. Para a fenomenologia, o mundo inclui muito 
mais coisas do que o alicerce físico, ou do que um complexo de coisas que captamos à nossa volta. Fenomenologicamente, o mundo seria uma área de relações formada a partir da polaridade entre o eu e o outro. Essa possibilidade de "criar mundos" é própria do ser humano e sua capacidade se expressar pela arte seria fundamental para o mesmo.

A arte e o pensamento são totalmente comunicáveis e interligados, estão intrinsecamente relacionados. Sendo a arte criação humana simbólica, ela está em permanente relação com outras esferas da realidade como aspectos culturais, históricos, sociais e etc. As obras de arte fazem parte do cotidiano das pessoas, são símbolos, e, para haver sua completa compreensão é necessário o conhecimento da história e da cultura que se relaciona a ela, é preciso se situar quanto ao "local" que possibilitou a sua criação. Contudo, a dimensão cultural não é elemento determinante na produção artística.

A literatura como produção artística pode dizer muito sobre determinado objeto, região ou situação. Como já foi dito a arte é um processo subjetivo de criação assim sendo por mais que ela possua laços com o contexto social e histórico em que ela se encontra em sua produção, a arte não imita a realidade, mas a transforma estabelecendo uma realidade própria e muito peculiar, como acontece em Cem anos de solidão. Por meio da arte é possível chegar a lugares, o indivíduo se torna capaz de transcender, como podemos perceber na afirmação da professora Oliveira sobre a utilização de todos os sentidos para que seja possível acessar o lugar:

A valorização do lugar provém de sua concretude; embora seja passível de ser engendrado ou conduzido de um lado para o outro, é um objeto no qual se pode habitar e desenvolver sentimentos e emoções. Tal realidade concreta é atingida por meio de todos os nossos sentidos, com todas as nossas experiências, tanto mediante a imaginação quanto simbolicamente. (OLIVEIRA, 2012, p. 12) 
O lugar como ambiente denso de laços afetivos e características emocionais marcantes pode e é representado na literatura, sendo esta produção artística. Macondo é o nosso exemplo de percepção espacial sendo um personagem do romance dotado com características mediadoras.

O conceito de espaço recebe, com fenomenologista francês Merleau-Ponty (1999), o papel e a importância de mediador dos sentidos e da construção da intersubjetividade. O que também pode ser aplicado à literatura, já que a mesma é uma forma de comunicação. Assim a forma como os sentidos comunicam manifestam a realidade defendida.

Temporalização de nosso ambiente terrestre, especialização de nossa finitude, a geografia se dirige, além do saber e da inteligência, ao próprio homem como pessoa e sujeito. Um elemento onde o homem não é o mestre interventor, geralmente inconsciente, na sua experiência geográfica: "a iluminação", assim observa Merleau-Ponty, "não está ao lado do objeto", ela é o "que nos faz ver o objeto", está no meio daquilo que somos e que ordinariamente nos escapa, e surge na paisagem. O mesmo lugar terrestre muda assim de valor segundo a estação ou a hora. (DARDEL, 2011, p. 40)

Como o geógrafo Dardel chama atenção na perspectiva de Merleau-Ponty, o olhar da geografia para o homem já é relativizado segundo o espaço pelo mesmo ocupado no círculo temporal. A percepção espacial pode ser definida como percepção, já que ela só se estabelece através da espacialidade, sendo ela física ou afetiva, do posicionamento de um campo sensorial. Pensar em uma percepção pontual seria um ato de enganação, pois o ato da percepção pressupõe todo processo de relação entre os sentidos e entre esses com o mundo que lhe é significativo, "a unidade do espaço só pode ser encontrada na engrenagem dos domínios sensoriais uns nos outros" (MERLEAU-PONTY, 1999, p. 300).

Corroborando com tal definição sobre percepção temos Husserl (1964), que propõe um significado mais amplo à "consciência que se reporta ao objeto temporal em 
sua unidade" (HUSSERL, 1964, p. 54), e afirma que esta é a "percepção adequada do objeto temporal" (HUSSERL, 1964, p. 54). Neste significado, "percepção" inclui não só a percepção ordinária como também uma série de retenções e um prolongamento no tempo, deixando de ser algo limitado a sentidos sensoriais. Ainda segundo Husserl (Cf. 1964, p. 43-44), fenomenologicamente, a percepção dá origem às impressões originárias, as quais podem ser entendidas como as impressões produzidas pelos conteúdos empíricos, mas não estes conteúdos mesmos.

Assim, por mais que Macondo não tenha um aporte físico, um local geográfico que pode ser visitado, pode ser concebido como lugar devido a sua representatividade e o papel que desempenha na obra Cem anos de solidão. O simbolismo representado por Macondo na narrativa dará os contornos necessários para que a história componha sua realidade específica. É um lugar com características próprias compondo relações de afetividade com os demais personagens, de fundamental importância para a narrativa.

\section{Habitar}

Quem disse que eu me mudei? Não importa que a tenham demolido: A gente continua morando na velha casa em que nasceu. (QUINTANA, 2013)

As ações de ir ou ficar, de buscar mudança ou permanecer em local de segurança, representadas muitas vezes por viagens ou por construções de moradias permeiam a vida humana. O geógrafo humanista Yi-Fi Tuan nos apresenta a diferenciação entre os diversos simbolismos que estão presentes nas relações com o espaço, como os lugares abertos e os fechados, como também podem ser observados na interpretação do romance em estudo. 


\begin{abstract}
"Aberto" e "fechado" são categorias espaciais significativas a muitas pessoas. Agorafobia e claustrofobia descrevem estados patológicos, mas espaços abertos e fechados também podem estimular sentimentos topofílicos. $O$ espaço aberto significa liberdade, a promessa de aventura, luz, o domínio público, a beleza formal e imutável; o espaço fechado significa a segurança aconchegante do útero, privacidade, escuridão, vida biológica. (TUAN, 1980, p. 30)
\end{abstract}

Essa concepção entre aconchego e liberdade é percebida no romance quando trata sobre a casa dos Buendía e suas características configuradas no mundo imaginativo. A protetora da casa no romance é Úrsula. A casa representa abrigo, união, lembranças, sonhos. Acima de tudo se configura como lugar, sendo este, lugar de proteção.

\begin{abstract}
Úrsula percebeu de repente a casa tinha se enchido de gente, que seus filhos estavam a ponto de casar e ter filhos, e que veriam obrigados a se dispersar por falta de espaço. Então pegou o dinheiro acumulado ao longo de longos anos de trabalho duro, assumiu compromissos com seus clientes e começou a ampliação da casa. (...) Naquele desconforto, respirando cal viva e melaço de alcatrão, ninguém entendeu direito como foi surgindo das entranhas da terra não apenas a maior casa que haveria no povoado, mas também a mais hospitaleira e fresca que jamais existiu na região do pantanal. (GARCíA MÁRQUEZ, 2016, p. 96-97)
\end{abstract}

Neste fragmento de texto do romance podemos perceber o papel que a casa desempenha na compreensão da personagem Úrsula, de modo geral seu papel típico, a casa reúne, abriga e protege. A intenção da matriarca com a ampliação do lar, juntamente com as melhorias em relação ao conforto tem por motivação não deixar que sua família se fragmente, disperse. Tanto que uma das características da família Buendía é o grupo ficar reunido na mesma casa. A casa, assim como Macondo, é um personagem e diz tanto para o desenvolvimento da história quanto qualquer outro que pisa em seu assoalho.

De todos os personagens que existem no romance, Úrsula Iguarán vive por mais tempo e enxerga mais gerações novas nascidas. Ela é a personificação da força feminina 
na criação e formação do autor colombiano. A personagem sobrevive a todos os três de seus filhos. Diferentemente da maioria de seus parentes, ela é imperturbável devido à sua ansiedade espiritual. Sendo assim, ela é provavelmente o indivíduo mais forte para viver em Macondo.

Ela dá acolhida à Rebeca, que é uma criança oriunda de estranhos, e a cria como sua filha. Além dela, Úrsula acolhe dezenas de estranhos à sua mesa. Ela tenta impedir que a casa caia aos pedaços. A missão desta personagem não é considerada fácil, haja vista que todos os seus descendentes se envolvem em guerras e escândalos.

Com Úrsula como matriarca, todavia, os Buendía estão ligados irrevogavelmente, para pior ou para melhor, em prol de manter a família em união. No entanto o medo de que sejam gerados bebês com rabos de porcos ou como iguanas assombra Úrsula e por isso ela chuta José Arcadio e Rebeca para fora da residência quando eles tentam fugir para viver como amantes.

Apesar de José Arcadio e Rebeca não serem parentes tecnicamente, Úrsula fica apavorada com a chance de que mesmo uma relação remotamente incestuosa teria como resultado alguém da família com rabo de porco. Seu próprio matrimônio com José Arcadio Buendía é considerado incestuoso, pois os mesmos são primos, como já dito. Ela permanentemente examina o comportamento de sua prole buscando falhas, muitas vezes avaliando o mesmo como pior do que se o filho em questão tivesse nascido com a cauda de porco.

Em razão de seu medo do incesto, Úrsula consiste em uma personagem contraditória, haja vista que ela mantém a família unida, porém tem pavor de que o incesto, o extremo da relação familiar, ocasione desgaste para a casa dos Buendía. 


\section{A casa dos Buendía}

A casa dos Buendía "desde um primeiro momento foi a melhor da aldeia, as outras foram arranjadas à sua imagem e semelhança." (GARCÍA MÁRQUEZ, 2007, p. 14). Segundo Fernandes, esta casa é como a cidade de Macondo "uma espécie de templo idealizado para a 'abertura' na realidade ilusória do mundo profano" (FERNANDES, 1991, p. 169). Na visão de Fonseca (1982), caracterizado com base na experiência, o lugar deveria ser considerado em suas distintas escalas, a iniciar pelo próprio lar, pela cidade, pela vizinhança, pela região e pelo Estado-nação.

Desta maneira colocamos em relevo o lar da família Buendía para se entender como é construído o sentido do lugar com base nas experiências vivenciadas por esta família. Este se trata de um dos espaços narrativos principais do romance Cem anos de solidão e debaixo de seu teto, grande parte da trama se desenvolve, é onde se entrecruzam as gerações, considerando que os Buendía são uma gente longeva, que engana a morte.

A casa nesses cem anos, assim como a cidade, foi para alguns um lugar de opressão e, para outros, um lugar de amor. Foi palco de desamores, de ódios, de amores proibidos, de amores incestuosos, de cobiça e, principalmente, de solidão. Viu surgir o primeiro Buendía de Macondo, e ainda, morrer o derradeiro, pois é nesta casa que termina a trágica sina dessa estirpe. Para se ler a casa dos Buendía, deve-se ler tanto a família quanto aqueles que se integraram ao seu destino, sejam por vontade própria ou não.

A casa constitui uma das principais forças de integração para as lembranças e os sonhos do indivíduo. Nesta integração, o princípio de ligação é o devaneio, conforme defende Bachelard (2008). Dessa forma para compreender e interpretar a casa da família 
Buendía procura-se enxergá-la como espaço de vivência, repleto de sentimentos, valores, lembranças dos que nela residem. É por causa disso que a casa na fenomenologia é, sobretudo, uma casa sonhada e por maior que seja o seu espaço, ela deve ser um corpo de pomba, uma choupana, uma crisálida, um ninho (Cf. BACHELARD, 2008). Percebe-se que a noção de Bachelard acerca do espaço é altamente poética e justificada pela alma humana.

Isto posto, quando se lê um texto literário, a imagem que é criada por meio dele, possui sentido em si mesma, no momento presente e de forma diferenciada em cada leitor, que passa a ser nesse momento também autor (Cf. LUCENA, 2008).

A casa, por exemplo, dá origem a infinitas imagens, que podem levar a outras imagens, que constituem atos poéticos ou, como afirma o filósofo, a "chama do ser" na imaginação. Na abundância de personagens que cobrem os cem anos deduzidos pela contagem do narrador, não existe um protagonista, existem protagonistas vivendo na casa. A cada geração aparecem novos Arcadios, Aurelianos, Amarantas, Remédios e Úrsulas.

Cada qual com suas particulares histórias, que vão se emaranhando umas nas outras até que uma teia seja formada, da qual ninguém escapará. Todos têm que cumprir um destino que já foi traçado antes de nascerem. As dimensões de tempo se multiplicam na obra. O espaço, por sua vez, é quase sempre a casa, considerando que é o ambiente que fixa o homem no tempo.

Desta forma, a casa dos Buendía está em todas as etapas da narrativa. A descrição do estado da casa condiz com a descrição do estado de vida da família. Sendo assim, no começo, o que se vê, é uma simples casa como eram simples as suas vidas. Com todas as demais vinte casas iniciais daquele povoado, era de taquara e barro. 
Tinha uma saleta ampla e bem iluminada, uma sala de jantar em forma de terraço com flores de cores alegres, dois quartos, um quintal com um castanheiro gigantesco, um jardim bem plantado e um curral onde viviam em comunidade pacífica os cabritos, os porcos e as galinhas. Os únicos animais proibidos não só em casa, mas também em todo o povoado, eram os galos de briga (GARCÍA MÁRQUEZ, 2007, p. 14)

Mesmo tendo sido construída com os mesmos materiais, disponíveis no local a casa dos Buendía era considerada a “(...) a melhor da aldeia e as outras (...) arranjadas à sua imagem e semelhança" (GARCÍA MÁRQUEZ, 2007, p. 14). A descrição da casa faz alusão a seu ato de fundação. Em alinhamento com Eliade (1992), percebe-se que o mundo que está em volta do homem, o mesmo no qual pode-se sentir a sua presença e a sua ação, sempre tem uma forma ou cópia que há em um nível cósmico mais elevado.

Em outros termos, isso significa que ao fundar sua casa, o homem acaba repetindo outro ato maior, outro ato cosmogônico, que consiste na criação do mundo. E este lugar de fundação é sempre o seu centro de mundo. Nota-se que os Buendía já guardam uma posição de relevo quando comparados aos demais moradores.

Um lugar é referente a um centro de valor, de apoio e alimento. A narrativa demonstra uma casa simples, contudo, e mesmo assim, é um lugar que acolhe e faz sonhar. As casas rústicas eram as que mais chamavam atenção de Bachelard em suas análises poéticas: "por elas meu devaneio habitava a casa essencial" (BACHELARD, 2008, p. 65). A casa, mesmo com sua simplicidade, é abrigo fortificante.

Com base na fenomenologia da imaginação de Bachelard (2008), o frescor de sua saleta iluminada pode ser sentido, concomitantemente, com o perfume das flores coloridas que enfeitam a murada, tais elementos cumprem seu papel de harmonizar o ambiente. Nota-se que o frescor era em razão da proximidade do rio. o local não foi 
escolhido de forma aleatória. Isso ratifica o argumento de Tuan (2012), quando advoga que lugares não são criações deliberadas, pois são construídos em prol de satisfazer as necessidades básicas.

A casa dos Buendía, igual às demais da aldeia, recebia sem esforço, duas forças vitais, a luz do sol e a água. Seus moradores podiam abastecer-se de água sem grande esforço e possuir uma casa bem-iluminada. Úrsula, a matriarca, com o auxílio das crianças, mantinha uma horta para alimentação da família, onde plantava taioba, banana, inhame, aipim, berinjela e cará. E para complementar o orçamento, fazia uns animaizinhos de caramelo para vender no povoado. Úrsula era uma mulher:

\footnotetext{
ativa, miúda, severa, (...) de nervos "inquebrantáveis, a quem em nenhum momento se ouviu cantar, parecia estar em todas as partes desde o amanhecer até a noite já bem avançada, sempre seguida pelo suave sussurro das anáguas de cambraia. Graças a ela, o chão de terra batida, os muros de barros sem caiação, os rústicos móveis de madeira construídos por eles mesmos estavam sempre limpos, e as velhas arcas onde se guardava a roupa exalavam um cheiro tênue de manjericão. (GARCÍA MÁRQUEZ, 2010, p. 14)
}

Segundo Bachelard, a casa configura-se como a própria pessoa, "sua forma e seu esforço mais imediato" (2008, p. 113). Em Cem anos de solidão, desde o começo da narrativa, a presença desta mulher se justapõe com a imagem da casa. Úrsula, em todos os sentidos, era quem mantinha a organização do lugar, e não somente em relação aos cuidados com a casa ou à providência de alimentos para a família, mas ainda quanto a salvaguardar sua harmonia e sua união. Dessa maneira, a matriarca cumpre o papel tutelar de guardar seus moradores. A casa harmoniosa configura, então, o bem-estar que devolve ao indivíduo a primitividade do refúgio. Neste sentido, para Bachelard, a casa constitui ninho, um ninho vivido. 
Em A Poética do Espaço (2008), Bachelard explica que a casa tanto é corpo quanto alma. Consiste no primeiro mundo do homem, antes de ser lançado no mundo. Como profetizam as metafísicas "apressadas", o ser humano é posto no berço da casa. E todas as vezes, em seus devaneios, a casa é considerada um grande berço. A vida inicia bem, inicia fechada, tutelada, acomodada no refúgio da casa.

O pensamento de Bachelard (2008) vai de encontro à descrição da casa dos Buendía. O lugar serviu para abrandar recordações do passado e sentimentos não desejáveis, trazidos de outros espaços. Agora as imagens são topofílicas.

\section{Considerações finais}

A casa é verdadeiramente o homem que habita nela. Em outros termos, é o homem quem impõe símbolos e valores de experiências à construção. No princípio da casa, as atitudes que marcam a narrativa são afeto, respeito, cumplicidade e amor. A Geografia Humanista frisa a valorização da experiência da pessoa ou grupo, de maneira a entender seu comportamento e formas de sentir em relação aos lugares, pois compreende que este contexto se trata de um espaço transformado em lugar.

Desta forma, observando-se o comportamento dos que moram na casa, notam-se as relações de cuidado e de amor entre eles: o sentimento de Aureliano pela jovem Remédios, materializado nos poemas que ele redige e que enchem a residência de amor; a cumplicidade de Aureliano e seu irmão José Arcádio. Tais relações harmoniosas se estendem aos habitantes da aldeia, por meio dos cuidados de José Arcadio Buendía com a comunidade.

A casa é, em escala distinta, o centro do mundo do ser humano. Segundo Eliade (2008), o simbologismo do mundo não faz alusão somente à nações, templos, cidades ou 
palácios. A habitação mais simples do homem, seja a casa do agricultor sedentário ou a do caçador nômade, é seu centro do mundo. Habitar um espaço consiste numa decisão religiosa. O ser humano assume a responsabilidade de criar, bem como organizar o mundo que decidiu habitar, consiste nisso a tutela do caos. Desta forma, não apenas "cosmiza o Caos, mas santifica seu pequeno Cosmos" (ELIADE, 2008, p. 61). Este simbolismo expressa o anseio de viver em um Cosmos 'santo' e 'puro', tal com era nos primórdios do mundo, no mítico instante da criação.

Neste espaço, tal qual aquele descrito por Bachelard (2008), começou-se a vida dos Buendía, no denominado espaço sagrado nas tradicionais sociedades. No decorrer da história de Cem anos de solidão, foi possível demonstrar a relevância da cada personagem na condição de experiência vivida, na qual os valores foram devidamente preservados e repassados aos seus moradores. Concomitantemente o leitor sente a casa ganhar sua identidade como lugar.

\footnotetext{
Sentir um lugar leva tempo: isso se faz de experiência em sua maior parte fugazes e pouco dramáticas, repetidas dia após dia e ao longo dos anos. É uma mistura de vistas, sons e cheiros, uma harmonia ímpar de ritmos naturais e artificiais, como a hora do Sol nascer e se pôr, de trabalhar e brincar. Sentir um lugar é registrado pelos nossos músculos e ossos. [...] Com o tempo uma casa deixa de chamar a nossa atenção; torna-se confortável e discreta como um velho par de chinelos. (TUAN, 2012, p. 224)
}

A vida familiar e a vida na comunidade no começo da narrativa constituem as imagens felizes da poética de Bachelard (2008). Nesta casa feliz, os filhos dos fundadores cresceram. À medida em que Macondo foi se modificando para cidade, a casa dos Buendía foi crescendo e passando a ter mais visibilidade, porém, proporcionalmente, foi perdendo no que se refere à afetividade entre seus moradores, evidenciando a solidão que seu povo carregava. 
O lugar é formado também por aspectos imateriais, as lembranças, as representações e também a nomeação constituem um lugar. Está intimamente ligado ao habitar que demanda envolvimento do ser humano com o mundo que o cerca, que o preenche, que o habita.

\section{Referências}

AGUIAR, Flávio; VASCONCELOS, Sandra Guardini T. (Org.). Angel Ramos: Literatura e Cultura na América Latina. Trad. Raquel la Corte do Santos, Elza Gasparotto. São Paulo: EdUSP, 2001.

BACHELARD, Gaston. A poética do espaço. São Paulo: Martins Fontes, 2008.

BANDEIRA, Manuel. Bandeira a Vida Inteira. Rio de Janeiro: Editora Alumbramento, 1986.

DARDEL, Eric. O homem e a terra: natureza da realidade geográfica. Trad. Werther Holzer. São Paulo: Perspectiva, 2011.

ELIADE, Mircea. O sagrado e o profano. Trad. Rogério Fernandes. São Paulo: Martins Fontes, 1992.

FERNANDES, Luiz Carlos. Aspectos do tempo circular de Cem anos de solidão. Revista Itinerários. no 2, 1991. (p.167-183).

FONSECA, Manuel da. O Largo. In: 0 fogo e as Cinzas. 9a.ed. Lisboa: Editorial Caminho, 1982.

GARCÍA MÁRQUEZ, Gabriel. Cien años de soledad: Edición comemorativa de 40 años. Madrid: Alfaguara, 2007.

Cem anos de solidão. Trad. Eric Nepomuceno. Rio de Janeiro: Editora Record, 2016.

. Yo no vengo a decir un discurso. Buenos Aires: Sudamérica, 2010.

HEIDEGGER, Marin. A origem da obra de arte. Trad. Maria C. Costa. Lisboa: Edições 70, 1977.

LUCENA, Karina de Castilhos. Macondo: além da terra firme. Dissertação de Mestrado. Caxias do Sul: UCS, 2008.

MERLEAU-PONTY. Maurice. Fenomenologia da Percepção. São Paulo: Martins Fontes, 1999. 
MARANDOLA JR, Eduardo. Humanismo e arte para uma geografia do conhecimento. Geosul, Florianópolis, v. 25, n. 49, p. 7-26, jan./jun. 2010.

OLIVEIRA, Lívia de. "O sentido de lugar". In MARANDOLA JR, Eduardo; HOLZER, Werther; OLIVEIRA, Lívia de. (Orgs.). Qual o espaço do lugar?: geografia, epistemologia, fenomenologia. São Paulo: Perspectiva, 2012, p. 3-15.

QUINTANA, Mário. Frase IV- A vida, a felicidade, o prazer. 2013. Disponível em: https://www.metro.org.br/editor/mario-quintana-frases-iv-a-vida-a-felicidade-o-prazer. Acesso em 07 de janeiro de 2019.

RAMA, Ángel. Transculturación narrativa en América Latina. Madrid: Siglo Veintiuno, 1987.

TUAN, Yi Fu. Topofilia: um estudo da percepção, atitudes e valores do meio ambiente. São Paulo: Difel, 2012.

Topofilia: um estudo de percepção ambiental, atitudes e valores. São Paulo: Editora DIFEL, 1980.

Recebido em 30 de outubro de 2019. 